\title{
Community pharmacy-based medication therapy management services: financial impact for patients
}

Sarah E. DODSON, Janelle F. RUISINGER, Patricia A. HOWARD, Sarah E. HARE, Brian J. BARNES. Received (first version): 5 -Oct-2011

Accepted: 19-Jul-2012

\begin{abstract}
${ }^{*}$
Objective: To determine the direct financial impact for patients resulting from Medication Therapy Management (MTM) interventions made by community pharmacists. Secondary objectives include evaluating the patient and physician acceptance rates of the community pharmacists' recommended MTM interventions.

Methods: This was a retrospective observational study conducted at 20 Price Chopper and Hen House grocery store chain pharmacies in the Kansas City metro area from January 1, 2010 to December 31, 2010. Study patients were Medicare Part D beneficiaries eligible for MTM services. The primary outcome was the change in patient out-ofpocket prescription medication expense as a result of MTM services.
\end{abstract}

Results: Of 128 patients included in this study, 68\% experienced no out-of-pocket financial impact on their medication expenses as a result of MTM services. A total of $27 \%$ of the patients realized a cost-savings (USD440.50 per year, $(\mathrm{SD}=289.69)$ ) while another $5 \%$ of patients saw a cost increase in out-of-pocket expense (USD255.66 per year, $(S D=324.48))$. The net financial impact for all 128 patients who participated in MTM services was an average savings of USD102.83 per patient per year $(S D=269.18, p<0.0001)$. Pharmacists attempted a total of 732 recommendations; 391 (53\%) were accepted by both the patient and their prescriber. A total of $341(47 \%)$ recommendations were not accepted because of patient refusal $(290,85 \%)$ or prescriber refusal $(51,15 \%)$.

Conclusions: Patient participation in MTM services reduces patient out-of-pocket medication expense. However, this savings is driven by only $32 \%$ of subjects who are experiencing a financial impact on out-of-pocket medication expense. Additionally, the majority of the pharmacists' recommended

\footnotetext{
Sarah E. DODSON. Community Pharmacy, Inc. Nevada, MO (United States). [at the time the study was conducted she was the community pharmacy resident for Balls Food Stores]

Janelle F. RUISINGER. Clinical Associate Professor.

School of Pharmacy, University of Kansas. Kansas City, KS (United States).

Patricia A. HOWARD. Professor and Vice Chair. School of Pharmacy, University of Kansas. Kansas City, KS (United States).

Sarah E. HARE. Clinical Pharmacist, Balls Food Stores/Hen House Pharmacy. Olathe, KS (United States). Brian J. BARNES. Associate Professor. School of Pharmacy, University of Kansas. Kansas City, KS (United States).
}

interventions (53\%) were accepted by patients and prescribers.

Keywords: Community Pharmacy Services. Medication Therapy Management. Drug Costs. United States.

\section{SERVICIOS DE GESTIÓN DE LA MEDICACIÓN EN FARMACIA COMUNITARIA: IMPACTO FINANCIERO PARA LOS PACIENTES}

\section{RESUMEN}

Objetivo: Determinar el impacto financiero directo para los pacientes resultando de las intervenciones de Gestión de la Medicación (MTM) hechas por farmacéuticos comunitarios. Los objetivos secundarios incluían evaluar las tasas de aceptación por pacientes y médicos de las recomendaciones de MTM de los farmacéuticos.

Métodos: Fue un estudio observacional retrospectivo realizado en 20 tiendas de la cadena de farmacias Price Chopper and Hen House de la zona metropolitana de Kansas City desde 1 de enero 2010 a 31 de diciembre 2010. Los pacientes en estudio eran beneficiarios de Medicare Part D elegibles para servicios de MTM. El resultado primario fue los cambios en gastos sufragados por los pacientes de la medicación prescrita como resultado de los servicios de MTM.

Resultados: De los 128 pacientes incluidos en el estudio, el $68 \%$ no experimentó impacto en sus gastos en medicación como resultado de los servicios de MTM. Un 27\% de los pacientes consiguió un ahorro (USD440,50 por año, $(\mathrm{SD}=289,69))$ mientras que otro $5 \%$ de pacientes vio incrementado su gasto en medicación (USD255,66 por año, $(\mathrm{SD}=324,48)$ ). El impacto financiero neto para los 128 pacientes que participaron en el estudio fue un ahorro medio de USD102,83 por paciente y año $(S D=269,18$; $\mathrm{p}<0,0001)$. Los farmacéuticos intentaron un total de 732 recomendaciones; 391 (53\%) fueron aceptadas tanto por pacientes como por prescriptor. Un total de $341(47 \%)$ recomendaciones no fueron aceptadas, por negativa del paciente $(290 ; 85 \%)$ o por negativa del prescriptor $(51 ; 15 \%)$.

Conclusiones: La participación de los pacientes en servicios de MTM reduce el gasto en medicamentos del paciente. Sin embargo, este ahorro se materializa sólo en un $32 \%$ de pacientes que sufren impacto financiero. Asimismo, la mayoría (53\%) de las intervenciones recomendadas 
por el farmacéutico fueron aceptadas por pacientes y prescriptores.

Palabras clave: Servicios Comunitarios de Farmacia. Gestión de la Medicación. Costos en medicamentos. Estados Unidos.

\section{INTRODUCTION}

Medicare is a United States federal health insurance for: individuals aged 65 years and older, individuals under age 65 years with certain disabilities and individuals at any age with EndStage Renal Disease (ESRD). Medicare provides hospital insurance (Medicare Part A), medical insurance (Medicare Part B) and prescription drug coverage (Medicare Part D) to those who qualify for benefits. Changes to the Medicare program were signed into law with the Medicare Prescription Drug, Improvement, and Modernization Act of 2003 (MMA 2003). ${ }^{1}$ This legislation requires prescription drug plans to offer high-risk Medicare Part D beneficiaries Medication Therapy Management (MTM). For 2010, high-risk Medicare Part D beneficiaries included those with multiple chronic disease states, taking multiple Medicare Part D covered medications, and likely to incur an annual cost of USD3,000 for prescription medications. ${ }^{2}$ The MMA 2003 did not outline specific details of MTM services but mandated that MTM programs must be "designed to reduce the risk of adverse events, defined as a specific service or group of services performed by pharmacists or other healthcare providers that improves medication use and reduces adverse drug events" ${ }^{3}$ Community pharmacists have been providing services similar to MTM for many years i.e., pharmaceutical care. However, unlike pharmaceutical care which does not have a reimbursement structure, MTM gives pharmacists the structure to provide services to Medicare Part D enrollees and receive reimbursement for these services. Although the MMA 2003 did not formally define MTM, a consensus of 11 national pharmacy organizations in 2004 agreed that MTM is broadly defined as "a service or group of services that optimize therapeutic outcomes for individual patients". 4 Expanding on this consensus, the American Pharmacists Association in partnership with the National Association of Chain Drug Stores Foundation outlined the specifics of MTM services. ${ }^{5}$ Pharmacists in community pharmacies are afforded unique opportunities to provide numerous MTM services including but not limited to: patient education and potential drug therapy issues (e.g. adverse reactions, poor adherence, unnecessary therapy, generic substitution, and not prescribed but necessary therapies based on disease state guidelines). Many potential benefits come with pharmacist involvement in MTM services. First and foremost, therapeutic outcomes from pharmacist involvement in MTM programs have been widely researched and definitively shown to be beneficial for the patient. ${ }^{6-8}$ Additional studies have looked at the cost savings to the healthcare system from pharmacist involvement in medication management as well as the financial impact for pharmacies conducting MTM services. Ramalho de Oliveira showed an estimated savings of USD2,913,850 to an integrated health care system over a 10 year period. $^{9}$ Another recent study evaluated net financial gains and losses for MTM services conducted by pharmacists and pharmacy students at an independent community pharmacy. During a 16 month period the pharmacy had a net financial gain of USD3.28 for providing MTM services. ${ }^{10}$

A study conducted in 2007 evaluated total medication cost savings from pharmacist interventions using a variety of delivery techniques including face-to-face encounters in a community pharmacy, phone interventions from a community pharmacy, a pharmacist-staffed call center, and direct patient education mailings. ${ }^{11}$ This study determined that drug product savings were highest when interventions were made in the community pharmacy setting, either face-to-face or telephonic as compared to interventions made by a pharmacist in a call center or educational mailing. While this study specifically evaluated medication costs per patient, it only identified total drug product costs saved, not patient out-of-pocket expense.

Previous studies have evaluated the acceptance rate of pharmacists' interventions. DeName et al observed a $61.4 \%$ provider acceptance rate of pharmacists' drug therapy recommendations in a freestanding pharmacist run clinic in Kentucky. ${ }^{12}$ Another study examined prescriber acceptance of pharmacists' drug therapy interventions in a community pharmacy. In this study prescribers accepted $47.4 \%$ of the pharmacists' recommendations. $^{13}$

Balls Food Stores is a family-owned supermarket chain local to the Kansas City area. There are 28 grocery stores with 20 pharmacies operating under both the Hen House and Balls Price Chopper banners. Balls Food Stores pharmacists (including residency trained and non-residency trained) and community pharmacy residents provide advanced patient care services including a travel vaccine clinic, immunizations (herpes zoster, pneumococcal and influenza), health screenings (osteoporosis, cholesterol, blood pressure, and blood glucose), and MTM Services. MTM services are offered to patients who are identified through the use of two separate third-party companies (Outcomes Pharmaceutical Health Care and Mirixa). These companies coordinate the provision of MTM services by contracting with Medicare Part D insurance plans to offer MTM services to the plan's eligible beneficiaries, and then alert the community pharmacist that a patient is eligible for MTM services. Balls Food Stores pharmacists and community pharmacy residents also provide services for the company's employee health initiative called Start Now. In the Start Now program, pharmacists and community pharmacy residents annually monitor Balls Food Stores employees' blood pressure, blood glucose, cholesterol, height, weight, and waist circumference. Additionally with Start Now, employees participate in disease management 
programs for diabetes and cardiovascular disease. There are also programs for lifestyle changes including weight management and smoking cessation.

The primary objective of this study was to determine the net financial impact on patient out-of-pocket prescription medication expense as a result of community pharmacists' MTM interventions. The secondary objective was to evaluate the patient and physician acceptance rates of the community pharmacists' recommended MTM interventions.

\section{METHODS}

This study was approved by the Institutional Review Board of The University of Kansas Medical Center. Patients included in this study were Medicare Part D members who had been previously identified as eligible for MTM services by Outcomes Pharmaceutical Health Care. Interventions conducted by community pharmacists at 20 grocery store chain pharmacies from January 1, 2010 through December 31, 2010 for MTM eligible patients were included in the study. Outcomes Pharmaceutical Health Care's electronic database and the pharmacies' prescription dispensing system records were used to collect the following data: age, gender, number of chronic prescription medications, number of interventions performed, patient and prescriber acceptance of suggested interventions and financial impact to the patient as a result of pharmacists' interventions.

The interventions assessed for this study included those which could potentially impact patient out-ofpocket prescription medication expense by the addition, reduction, or elimination of a prescription medication. This included elimination of unnecessary drug therapy, generic substitutions, and identification and substitution to a preferred brand name medication based on the patient's insurance plan payment tiers. In addition, this study evaluated prescription medication costs added as a result of pharmacists' interventions such as the addition of needed therapies based on disease state guidelines, or any substitution in medication therapy which resulted in a higher out-of-pocket cost for the patient. Any other prescription medication therapy modification resulting in a change in out-of-pocket expense for the patient was also assessed, including changes as a result of drug-drug interactions, suboptimal drug selection, or adverse drug reactions. Interventions involving over-the-counter products were excluded from evaluation due to cost variation among these products. This study only evaluated direct prescription medication costs to the patient. Other costs avoided by the patient as a result of pharmacists' interventions, such as the cost for an additional physician's office visit, emergency room visit, or hospital stay were not evaluated.

The patients' and physicians' acceptance rate of the pharmacist recommended MTM interventions was determined by evaluating electronic records completed by pharmacists performing MTM services. The pharmacists documented all interventions recommended to both patients and physicians and subsequently documented the patients and physicians responses to the recommended interventions.

\section{Inclusion and Exclusion Criteria}

Patients who participated in any aspect of MTM services during the study period of January 1, 2010 through December 31, 2010 were included in this study. For the purposes of this study, MTM participants were defined as patients who participated in any aspect of MTM services, including comprehensive medication therapy reviews or any individual pharmacist interventions which were identified by both the pharmacists and Outcomes Pharmaceutical Health Care. Interventions were identified during the course of a comprehensive medication therapy review and also through routine encounters with the patient during traditional pharmacist dispensing workflow. Patients did not have to participate in every aspect of MTM services to be included in the study. Patients who refused any individual component of MTM services were still included if they consented to another pharmacist intervention or comprehensive medication therapy review session. Patients who refused all aspects of MTM services were excluded from the study.

\section{Data Analysis}

The financial impact of the MTM intervention from the patients' perspective was calculated for each patient as an increase or decrease in patient out-ofpocket expenses. Using SAS (version 9.2) this variable was assessed for normality. As the data was not normally distributed, a two-sided WilcoxonRank-Sum test and an a priori alpha level of 0.05 was used to test the null hypothesis that the financial impact was zero, representing no change in expense.

\section{RESULTS}

A total of 284 patients across 20 pharmacies were eligible for MTM services. Of these 284 patients, $128(45 \%)$ participated in MTM services and were included in this study (Figure 1). There were 116 patients $(41 \%)$ who declined all aspects of MTM services and 40 patients (14\%) who were not offered MTM services. Patients who participated in MTM services were primarily female $(72.7 \%)$ with a mean age of 74.4 years $(S D=9.4)$ (Table 1). The mean number of baseline chronic prescription medications for these patients was $10.0(S D=4.2)$.

Overall, of the 128 patients included in the study 87 $(68 \%)$ did not see a direct financial impact from MTM services. The remaining 41 (32\%) patients had a change (increase or decrease) in out-ofpocket expense: Thirty four (27\%) of these patients saw a decrease in medication expenses, with an average cost reduction of USD440.50 (SD=289.69)

\begin{tabular}{|l|c|}
\hline $\begin{array}{l}\text { Table 1. Baseline Characteristics } \\
\text { Participating in MTM Services }(\mathrm{n}=128)\end{array}$ & \\
\hline Average Age in years (SD) & $74.4(9.4)$ \\
\hline Female (\%) & 72.7 \\
\hline Baseline Medications (SD) & $10.0(4.2)$ \\
\hline
\end{tabular}




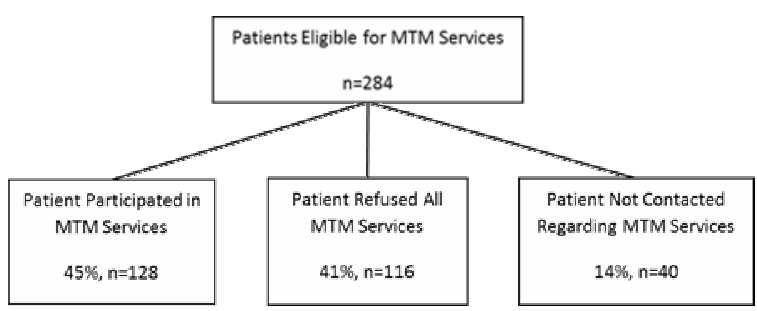

Figure 1: Patient Participation in MTM Services

per patient per year. Seven $(5 \%)$ patients experienced an increase in medication expenses with an average cost increase of USD255.66 $(\mathrm{SD}=324.48)$ per patient per year. The net financial impact for all 128 patients was a savings of USD102.83 (SD=269.18) per patient per year $(p<0.001)$. No difference was found in the number of chronic prescription medications per patient compared to baseline.

Pharmacists attempted a total of 732 interventions throughout the year for the 284 MTM eligible patients (Figure 2). Of all interventions attempted, $53 \%(391 / 732)$ of these interventions were approved by both patient and physician, and among these approved interventions 17\% (68/391) were deemed to have a potential financial impact on patient out-of-pocket expense. The most common intervention affecting out-of-pocket medication expenses was a change in medication (82\%, $56 / 68)$, followed by addition of a needed therapy based on disease state guidelines $(12 \%, 8 / 68)$, and discontinuation of a duplicate or unnecessary therapy $(6 \%, 4 / 68)$. Interventions which were found to not impact patient medication expenses included those involving patient education, dose change, and medication administration (i.e. inhaler technique). The remaining $47 \%$ of interventions (341/732) were not implemented due to patient or prescriber refusal of the pharmacist's intervention. Any financial impact resulting from medication adherence was not evaluated as this study did not track medication adherence.

\section{DISCUSSION}

Our findings demonstrate that MTM services performed by community pharmacists are overall a cost savings event regarding patient out-of-pocket medication expenses. However, when a financial impact is realized, it is driven by only $32 \%$ of the patients. DeName et al showed similar results in a study involving patients within a health plan. ${ }^{12}$ The pharmacist interventions resulted in an average annual savings of USD166.20 to each patient and an annual savings to the health plan of USD163.08 per patient. Another study conducted in an employer setting demonstrated an average direct savings to the employer of USD253 per patient per year as a result of pharmacist medication related interventions. These pharmacist interventions also saved the company an average of USD1011 per patient per year in direct and indirect health costs. ${ }^{14}$

While our study demonstrated an overall decrease in out-of-pocket expenses as a result of MTM services, a few of our patients experienced an increase in out-of -pocket expenses. We believe it is possible that the costs added for patients in this study may actually provide a cost savings in the long-term through improved medication use. For example, the addition of an inexpensive angiotensin converting enzyme inhibitor (ACE) for blood pressure control and nephron-protection in a patient with diabetes may increase patient out-of-pocket expense immediately; however the benefit of the medication in preventing subsequent diseaserelated complications may save the patient and the healthcare system significant costs in the future. $\mathrm{Li}$ et al reported that ACE inhibitors provide an overall cost-savings when used by patients with diabetes for hypertension control and to prevent ESRD. ${ }^{15}$

This study also assessed the patients and prescribers acceptance rate of pharmacist interventions. The acceptance rate in this study was similar to the acceptance rates previously reported by similar studies.

\section{Limitations}

Our study had several limitations that warrant discussion. First, our study only assessed the financial impact for patients as a result of prescription medication expenses. We did not evaluate non-prescription medication changes due to wide cost variances of these products. Other factors that may have contributed to a financial savings for patients such as prevention of hospitalizations, emergency room visits, and doctors' office visits were not assessed. Another limitation was our inability to assess medication adherence due to the limited time frame of this study. A potential increase in patient out-of-pocket expense exists if a patient had improved medication adherence as a result of pharmacists' interventions and therefore re-filled a medication more frequently. However, as our study was restricted to a 12 month period, we could not fully assess the true impact of a medication adherence intervention, especially if the intervention had occurred late in the year.

\section{CONCLUSIONS}

In this community-based setting, patient participation in MTM services was found to be an overall cost savings event relative to patient out-ofpocket medication expense. Future studies should evaluate changes in non-prescription medication expenses as a result of pharmacists' interventions as well as prescription medication expenses. Likewise, future studies should evaluate medication adherence as improved adherence can significantly impact patient out-of-pocket medication expenses.

\section{CONFLICT OF INTEREST}

Received financial support from 2011 American Pharmacists Association Foundation Incentive Grant for Residents and their Preceptors.

All authors declare no conflict of interest with this project. 


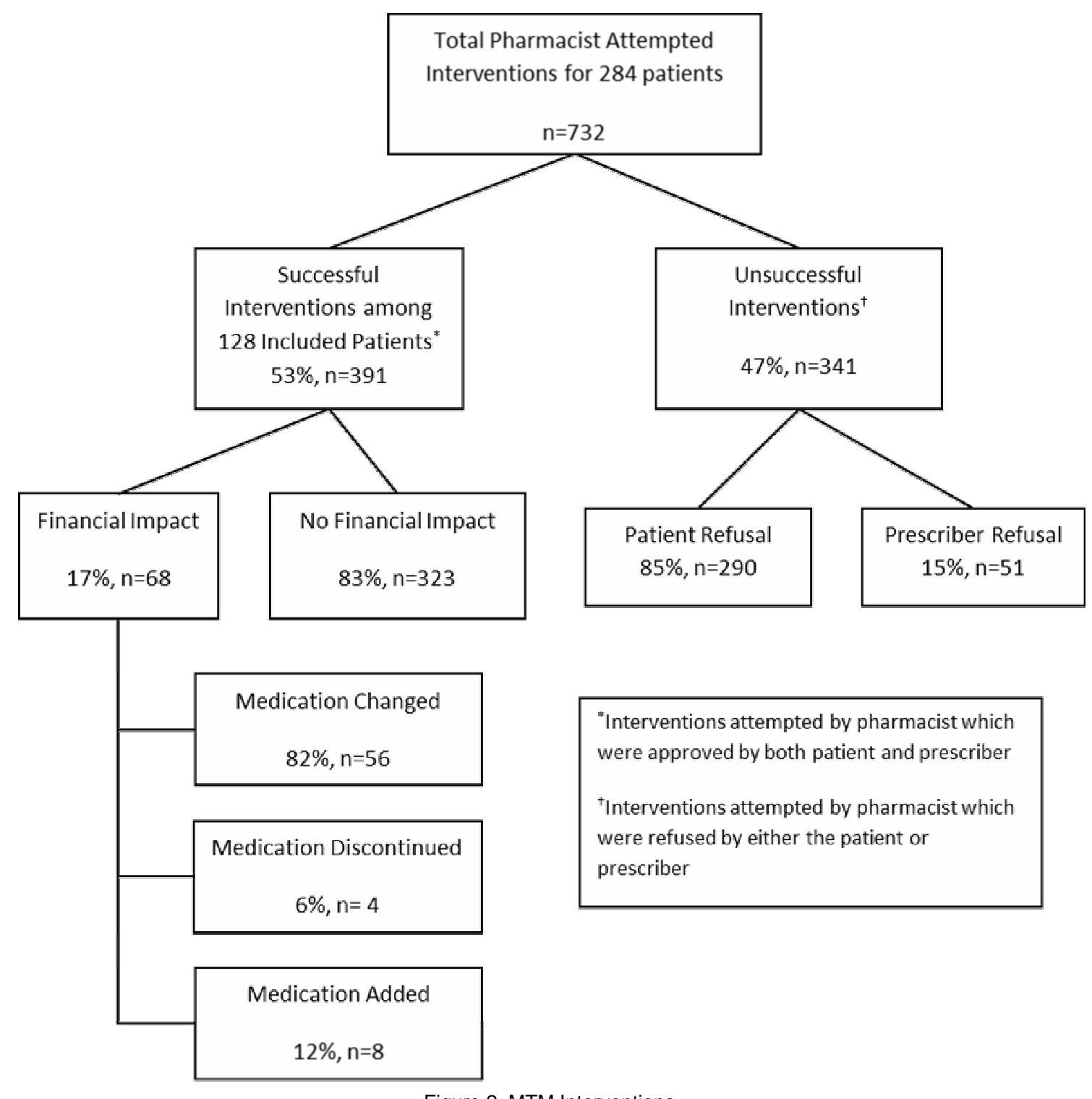

Figure 2. MTM Interventions

\section{References}

1. Public Law 108-173-Dec. 8, 2003. Medicare Prescription Drug, Improvement, and Modernization Act of 2003. Accessed at http://www.gpo.gov/fdsys/pkg/PLAW-108publ173/pdf/PLAW-108publ173.pdf, May 16, 2012.

2. Prescription Drug Benefit Manual Chapter 7 - Medication Therapy Management and Quality Improvement Program accessed at https://www.cms.gov/Medicare/Prescription-DrugCoverage/PrescriptionDrugCovContra/downloads/Chapter7.pdf, May 16, 2012.

3. Federal Register Vol. 70, No. 18 accessed at http://www.gpo.gov/fdsys/pkg/FR-2005-01-28/pdf/05-1321.pdf, May 16, 2012.

4. Bluml BM. Definition of medication therapy management: development of professionwide consensus. J Am Pharm Assoc. 2005;45(5):566-572.

5. American Pharmacists Association and National Association of Chain Drug Stores Foundation. Medication therapy management in pharmacy practice: Core elements of an MTM service model (version 2.0). J Am Pharm Assoc. 2008;48(3):341-353.

6. Johannigman MJ, Leifheit M, Bellman N, Pierce T, Marriott A, Bishop C. Medication therapy management and condition care services in a community-based employer setting. Am J Health-Syst Pharm. 2010;67(16):1362-1367.

7. Bunting BA, Cranor CW. The Asheville Project: Long-term clinical, humanistic, and economic outcomes of a community-based medication therapy management program for asthma. J Am Pharm Assoc. 2006;46(2):133-147.

8. Planas LG, Crosby KM, Mitchell KD, Farmer KC. Evaluation of a hypertension medication therapy management program in patients with diabetes. J Am Pharm Assoc. 2009;49(2):164-170.

9. Ramalho de Oliveira D, Brummel AR, Miller DB. Medication Therapy Management: 10 years of experience in a large integrated health care system. J Manag Care Pharm. 2010;16(3):185-195. 
10. McDonough RP, Harthan AA, McLeese KE, Doucette WR. Retrospective financial analysis of medication therapy management services from the pharmacy's perspective. J Am Pharm Assoc. 2010;50(1):62-66.

11. Winston S, Lin YS. Impact on drug cost and use of Medicare Part $D$ of medication therapy management services delivered in 2007. J Am Pharm Assoc. 2009;49(6):813-820.

12. DeName B, Divine H, Nicholas A, Steinke DT, Johnson CL. Identification of medication-related problems and health care provider acceptance of pharmacist recommendations in the DiabetesCARE program. J Am Pharm Assoc. 2008;48(6):731-736.

13. Doucette WR, McDounough RP, Klepser D, McCarthy R. Comprehensive medication therapy management: Identifying and resolving drug-related issues in a community pharmacy. Clin Ther. 2005;27(7):1104-1111.

14. Johannigman MJ, Leifheit M, Bellman N, Pierce T, Marriott A, Bishop C. Medication therapy management and condition care services in a community-based employer setting. Am J Health-Syst Pharm. 2010;67(16):1362-1367.

15. Li R, Zhang P, Barker LE, Chowdhury FM, Xuanping Z. Cost-effectiveness of interventions to prevent and control diabetes mellitus: A systematic review. Diabetes Care. 2010;33(8):1872-1894. 